\title{
Panel Management to Improve Smoking and Hypertension Outcomes by VA Primary Care Teams: A Cluster-Randomized Controlled Trial
}

\author{
Mark D. Schwartz, MD ${ }^{1,2}$, Ashley Jensen, MPA ${ }^{1,3}$, Binhuan Wang, $P h D^{2}$, Katelyn Bennett, MPH ${ }^{1,3}$, \\ Anne Dembitzer, $M D^{1,3}$, Shiela Strauss, $P h D^{4}$, Antoinette Schoenthaler, EdD2, Colleen Gillespie, $P h D^{3}$, \\ and Scott Sherman, $M D^{1,2}$ \\ 'VA New York Harbor Health Care System, New York, NY, USA; 'Department of Population Health, New York University School of Medicine, New \\ York, NY, USA; ${ }^{3}$ Department of Medicine, New York University School of Medicine, New York, NY, USA; ${ }^{4}$ New York University College of Nursing, New \\ York, NY, USA.
}

BACKGROUND: Panel Management can expand prevention and chronic illness management beyond the office visit, but there is limited evidence for its effectiveness or guidance on how best to incorporate it into practice.

OBJECTIVE: We aimed to test the effectiveness of incorporating panel management into clinical practice by incorporating Panel Management Assistants (PMAs) into primary care teams with and without panel management education.

DESIGN: We conducted an 8-month cluster-randomized controlled trial of panel management for improving hypertension and smoking cessation outcomes among veterans.

PATRICIPANTS: Twenty primary care teams from the Veterans Affairs New York Harbor were randomized to control, panel management support, or panel management support plus education groups. Teams included 69 clinical staff serving 8,153 hypertensive and/or smoking veterans.

INTERVENTIONS: Teams assigned to the intervention groups worked with non-clinical Panel Management Assistants (PMAs) who monitored care gaps and conducted proactive patient outreach, including referrals, mail reminders and motivational interviewing by telephone.

MAIN MEASURES: Measurements included mean systolic and diastolic blood pressure, proportion of patients with controlled blood pressure, self-reported quit attempts, nicotine replacement therapy (NRT) prescriptions, and referrals to disease management services.

KEY RESULTS: Change in mean blood pressure, blood pressure control, and smoking quit rates were similar across study groups. Patients on intervention teams were more likely to receive NRT (OR=1.4; $95 \%$ CI 1.2-1.6) and enroll in the disease management services MOVE! $(\mathrm{OR}=1.2 ; 95 \% \mathrm{CI}$ 1.1-1.6) and Telehealth $(\mathrm{OR}=1.7,95 \%$ CI 1.4-2.1) than patients on control teams.

CONCLUSIONS: Panel Management support for primary care teams improved process, but not outcome variables among veterans with hypertension and smoking. Incorporating PMAs into teams was feasible and highly valued

Received April 14, 2014

Revised November 10, 2014

Accepted January 16, 2015

Published online February 10, 2015 by the clinical staff, but clinical impact may require a longer intervention.

KEY WORDS: panel management; hypertension; smoking; PCMH.

J Gen Intern Med 30(7):916-23

DOI: $10.1007 / \mathrm{s} 11606-015-3204-\mathrm{y}$

(c) Society of General Internal Medicine 2015

\section{INTRODUCTION}

To fulfill the promise of medical homes, practices must expand from visit-based to population-based care. Health reform is promoting accountability for population health outcomes, and incentivizing strategies to measure and improve panel-level outcomes. ${ }^{1}$ Practices that adopt this type of population-level approach are more likely to follow recommendations for disease-specific testing and adhere to evidence-based guidelines than those maintaining a visit-based approach to care. ${ }^{2-6}$ One emerging approach is Panel Management, a "set of tools and processes for population care that are applied systematically at the level of the primary care panel, with physicians directing proactive care for their empaneled patients."7,8 Population-based panel management has improved clinical processes and patient outcomes for diabetes mellitus (DM), depression, and hypertension (HTN), as well as key care processes for preventive care. ${ }^{3,9-11}$ However, training, tools, and support for clinical teams implementing panel management tasks are limited. While panel management holds great potential for improving preventive and chronic disease management, little is known about which strategies are most effective to improve outcomes.

In 2010, the Department of Veteran Affairs (VA) launched a nation-wide transformation to create medical homes called Patient-Aligned Care Teams (PACT). ${ }^{12}$ In the PACT model, panels of patients are cared for by teams led by a primary care provider (PCP), a nurse care manager (RNCM), a Licensed Practical Nurse (LPN), and a clerk, with support from an extended team including a social worker, pharmacist, dietician, and psychologist. In this model, nurses are expected to expand their traditional roles to become care managers and to 
facilitate panel management. However, it is uncertain if teams have the skills, tools, or time to successfully manage panels. Early analysis of the PACT demonstration sites revealed challenges in accessing accurate and actionable patient data and insufficient time for such efforts. ${ }^{13}$ Thus, there is a pressing need to develop and test panel management strategies, including whether additional education is needed or simply having staff resources is sufficient to improve panel health.

Hypertension and smoking affect substantial numbers of veterans, lead to significant morbidity and health care costs, and have effective treatments that are not fully optimized. ${ }^{14}$ Hypertension prevalence has increased by $25 \%$ since 2000 , now affecting more than 1.7 million veterans. ${ }^{15}$ Only one-third of hypertensive patients in the US achieve blood pressure (BP) control. ${ }^{16}$

Smoking is the leading preventable cause of morbidity and mortality among veterans ${ }^{17}$ accounting for up to $21 \%$ of all health care costs in VA. ${ }^{18}$ Smoking cessation treatment is a national VA priority, as treatment is feasible and effective, but underutilized. While VA has become a model for tobacco control, there is still a need for new strategies to help smokers quit. $^{19}$

\section{OBJECTIVE}

To test the effectiveness of panel management, we tested the impact of incorporating Panel Management Assistants (PMA) into primary care teams with and without panel management education on hypertension and smoking outcomes.

\section{METHODS}

\section{Design Overview}

We conducted an 8-month, pragmatic, cluster-randomized, three-arm controlled trial to assess the impact of the addition of a PMA and of team-based panel management education on hypertension and smoking cessation processes and outcomes for patients enrolled in primary care clinics at two VA New York Harbor Healthcare System (VA NYHHS) campuses. The intervention took place from 1 January to 31 August 2012. The intervention duration was shortened from 12 to 8 months for two reasons. The start was delayed to permit the teams to be restructured as VA rolled out the PACT model nationally in late 2011. The study was further shortened when Hurricane Sandy closed the hospital for 6 months and disrupted routine primary care. ${ }^{20}$ This study was approved by VA's Institutional Review Board and Research and Development Committee, without the need for consent from individual patients for the intervention, as this was viewed as a primary care, team-based, clinical process. Patient consent to the mailed survey was implied by their response.

\section{Setting and Participants}

As part of VA's PACT transformation, primary care at VA NYHHS was modified in December 2011, restructuring into new PACT teams, each with one to five PCPs, one RNCM, one LPN, and one clerk. Each PACT had one full-time equivalent PCP caring for a panel of up to 1,200 patients. All 51 PCPs and 18 RNCMs assigned to the 20 PACT teams were invited to participate in the study. We excluded 22 other PACTs (three medical resident, two Geriatrics, two Women's Health, six Home-Based PC, four Mental Health, and five Subspecialty) to focus on primary care teams.

Patients were attributed to a PACT panel if they had at least two visits to the PCP within 2 years. Panels were updated monthly. We identified hypertensive patients using ICD-9 codes from two or more encounters within the previous 2 years and smokers using the routine electronic screening reminder in the medical record.

\section{Randomization}

PACTs were stratified by site (Brooklyn or Manhattan) and by solo versus multiple PCP, and then randomly assigned to one of three groups: Control, PMA Support, and PMA Support plus targeted panel management education (Fig. 1). We randomized at the PACT team level to limit contamination, as RNCM are assigned to a team that can have multiple PCPs.

\section{Interventions}

Each of the six PMAs were assigned to two PACTs within the same intervention group (PMA or PMA-plus-Education) to minimize contamination. PMAs were college graduates with no clinical training. They underwent a 1-month orientation that covered basic clinical issues in hypertension and smoking, and skill development in panel management, VA's electronic medical record (EMR) and administrative tools, motivational interviewing and Brief Action Planning. ${ }^{21}$

It was not possible to blind PACT staff or PMAs to their team's allocation. However, study outcomes were evaluated by abstracting clinical data from VA's EMR by researchers blind to patients' study allocation. Secondary patient outcomes were evaluated by self-administered questionnaires, facilitated by researchers unaware of study allocation. Patients were not individually consented for the intervention, and thus were unaware of the study allocation of their provider or clinical team. When PMAs interacted with patients, they introduced themselves as assistants to the team, working on behalf of the patient's PCP, and did not mention study group allocation.

PMAs systematically reviewed panel data for their assigned PACTs to identify patients with gaps in care (e.g., patients lost to follow-up, prescriptions not filled or refilled, missed appointments, blood pressure out of control, etc.). They joined biweekly PACT meetings to review patient lists and propose panel management strategies using a toolkit developed for the study, and then conducted patient outreach by phone and 
VA New York Harbor Patient Aligned Care Teams ( $N=42$ teams)
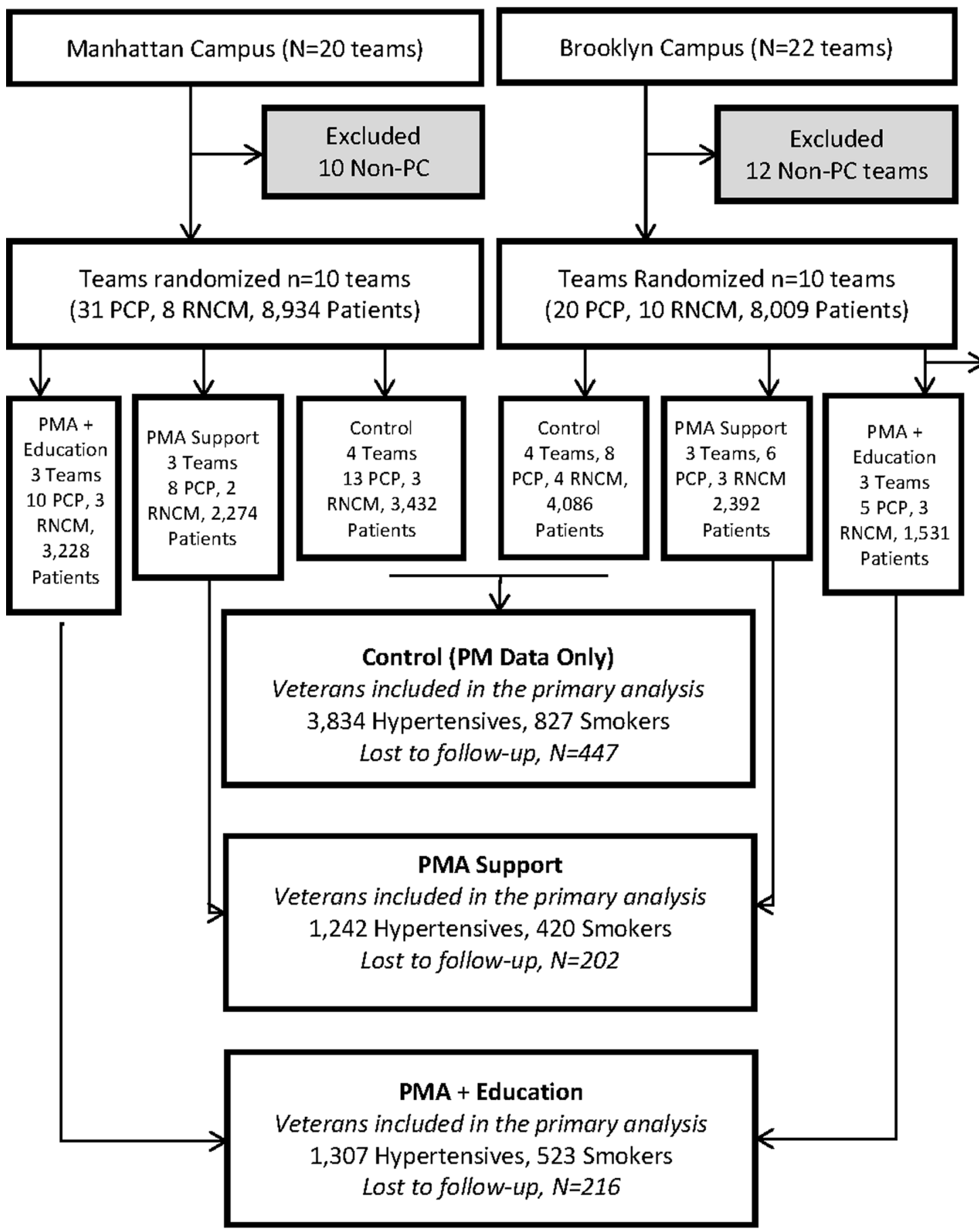

Excluded 1 PCP (Withdrew consent)

\section{Abbreviations:}

PCP - PC Provider (MD, NP or PA)

RNCM - Nurse Care Manager Non-PC - Teams not in PC 
mail. $^{22}$ The toolkit included strategies in five general areas: continuity, connection to clinical resources, behavior change counseling, adherence support, and patients with special needs. In addition to the toolkit, PMAs had access to the Primary Care Almanac, an electronic tool for viewing panel level patient information, in order to implement outreach strategies. ${ }^{23}$ PMAs met weekly with the study coordinator to review and standardize panel management implementation. These meetings maintained intervention fidelity by sharing toolkit strategies used, lessons learned, and ensuring that each PMA was executing each toolkit strategy over the course of the intervention. PMAs also had access to a physician investigator at each campus to answer any questions.

PMA-plus-Education teams received the PMA support described above, plus five 20-minute workshops during PACT meetings. These case-based sessions were led by a physician or education specialist and addressed: 1) working in multidisciplinary teams, 2) practicing panel management, and 3) leveraging the clinical microsystem. The curriculum was developed based on relevant literature, VA guidelines for PACT implementation, and effective models of provider education. ${ }^{26}$ We utilized the PACT's list of uncontrolled hypertensive patients to enhance understanding of panel management. Teams discussed data quality, interpretation, and care gaps and then prioritized a set of potential interventions. Sessions also addressed team motivation and barriers to population-based care. At each session, leaders led discussions about role responsibilities and effective intra-team communication.

Control teams were provided with monthly lists of current smokers and patients with uncontrolled hypertension. They did not have access to PMAs and did not participate in studyspecific panel management education. During the intervention, all PACT staff members, regardless of study group, were required to participate in three half-day, large-group training exercises in PACT principles and skills, including panel management, organized by VA NYHHS.

\section{Measures}

The primary clinical outcomes for hypertension were the mean systolic and diastolic BP, using each patient's 3-month average of $\mathrm{BP}$ readings at baseline and post-intervention. We obtained all BP readings from outpatient visits from VA's Corporate Data Warehouse for all hypertensive patients enrolled in study PACTs, excluding emergency department and day-ofprocedure readings. Mean BP was used to calculate the proportion of hypertensive patients with uncontrolled BP, defined as systolic $>140 \mathrm{mmHg}$ or diastolic $>90 \mathrm{mmHg}$, at baseline and post-intervention.

VA's EMR reminds staff annually to determine a patient's smoking status. While useful for identifying past and current smokers, the reminder data does not provide a systematic record of quit attempts and cessation. Therefore, we used self-reported quit attempts and current smoking status via mailed survey as our primary smoking outcome. Patients were asked to report if they smoked in the previous 30 days, quit for at least 1 day, and quit for at least 1 week. We surveyed a randomly selected sample of 1,000 patients (hypertensive or current smokers) at baseline, stratified by PACT. Postintervention we re-surveyed 250 of the respondents from the baseline survey plus a new randomly selected cross section of 750 patients, again stratified by PACT.

Secondary clinical outcomes for hypertension included patient participation in the VA disease management services of MOVE! (VA's exercise and weight management program), and VA's Telehealth, home-based electronic BP monitoring. For smoking, we measured the number of prescriptions for nicotine replacement therapy (NRT) medications during the 8-month study period using the VA's EMR.

Secondary process outcomes were measured in online surveys of PACT staff at baseline and again 2 months postintervention. These included attitudes toward panel management, sufficiency of training in panel management, and working with PMAs. Staff survey measures and outcomes are reported elsewhere. ${ }^{25}$ Using weekly tracking forms, PMAs recorded the team meeting frequency, panel management strategies used, patient populations targeted for interventions, outreach performed, and number of patients reached.

\section{Statistical Analysis}

Analyses were done in accordance with the CONSORT statement ${ }^{27}$ and its extensions to cluster and pragmatic trials, ${ }^{28,29}$ using SAS, version 9.3..$^{30}$

The unit of intervention was the PACT team, but the primary outcomes for the study were measured at the patient level, aggregated to the PCP. After computing unadjusted models, we accounted for clustering of patients within PCP panels by calculating intraclass correlation coefficients (ICC) for smoking and hypertension outcomes and using randomeffect models (PROC MIXED).

To determine the primary outcomes for hypertension, we compared mean systolic and diastolic BP post-intervention among the study arms, controlling for mean BP at baseline. We compared the proportion of patients with uncontrolled BP post-intervention by study arm, controlling for baseline rate by logistic regression, also accounting for the team clustering effect (PROC GENMOD).

In secondary analyses, we assessed BP outcomes among patients with uncontrolled hypertension at baseline, as they were more likely to interact with a PMA during the intervention. We assessed dose response by correlating the proportion of patients with controlled BP (BP <140/90) with the number of times the PACT team met with a PMA, and the percentage of hypertensive patients reached by phone and by mail by PMAs. To account for missing readings, we carried forward the last BP reading for post-intervention and used the earliest available reading for baseline. This missing data imputation did not alter the results. 
To assess smoking outcomes, we used logistic regression to compare rates of tobacco abstinence, quit attempts, and NRT prescriptions by study arm. We compared process outcomes among the study groups of MOVE and Telehealth participation, defined as the number of hypertensive patients with at least one completed MOVE! session or enrollment in Telehealth during the study period. We also assessed the proportion of smoking and hypertensive patients in each study group with at least one regular (not including urgent care, walk-in clinic or telephone visit) primary care appointment within the last 6 months from the study's end date.

\section{Post Hoc Power Analysis}

The study had $80 \%$ power (alpha $=0.05$ ) to detect an overall difference of $2.7 \mathrm{mmHg}$ in systolic $\mathrm{BP}$ and a $1.7 \mathrm{mmHg}$ difference in diastolic BP in all participants, and a difference of $3.9 \mathrm{mmHg}$ systolic BP and $2.4 \mathrm{mmHg}$ diastolic BP for participants with uncontrolled HTN at baseline. The study had $80 \%$ power (alpha $=0.05$ ) to detect a minimum $14 \%$ relative difference in rates of smoking in the last 30 days between the control and intervention arms. All power calculations accounted for clustering at the team level using the most conservative estimated intraclass correlation coefficient (ICC) from the health services literature of $0.013 .{ }^{31}$

\section{RESULTS}

\section{Response Rates}

All 20 eligible PACT teams were randomly allocated to the three study arms (Fig. 1). All 18 RNCMs and 50/51 eligible PCPs participated in the study. The non-participating PCP's team was in the PMA education group. While the PMA did not intervene with his/her patients, patients attributed to this PCP's panel remained in the intervention group as allocated for all analysis, consistent with the most conservative intent-to-treat approach, since all PCPs on the team shared team members. Of the 8,150 patients assigned to a participating team, (865) $11 \%$ were lost to follow-up (10\% in the control group, $12 \%$ in each of the intervention groups). Patients were lost to follow-up if they had no blood pressure readings after the baseline period, or if they left the practice. The overall patient survey response rate was $50 \%$ at baseline and $52 \%$ post-intervention. For the staff survey, $65 \%$ responded to both the baseline and postintervention survey, with no difference between PCPs and RNCMs. There were no significant differences among the three study groups in response rates for patients or staff.

\section{Baseline Characteristics}

Clinical staff were predominately female, between 45 and 64 years old, and worked full-time at the VA for over 10 years (Table 1). Study teams had a mean of 847 patients, $91 \%$ of whom were male with a mean age of 63 years (Table 1). Fortyeight percent of the patients had hypertension, and $22 \%$ of these
Table 1 Baseline Clinical Staff and Patient Characteristics by Study Arm

\begin{tabular}{|c|c|c|c|}
\hline \multirow[t]{2}{*}{$\%$ with characteristic } & \multicolumn{3}{|c|}{ Study arm } \\
\hline & $\begin{array}{l}\text { Control } \\
(8 \text { teams })\end{array}$ & $\begin{array}{l}\text { PMA } \\
\text { Support } \\
\text { (6 teams) }\end{array}$ & $\begin{array}{l}\text { PMA+ } \\
\text { Education } \\
\text { (6 teams) }\end{array}$ \\
\hline \multicolumn{4}{|l|}{ Staff Characteristics ${ }^{\mathrm{a}}$} \\
\hline Number & 28 & 19 & 22 \\
\hline \multicolumn{4}{|l|}{ Role (\%) } \\
\hline Primary Care Provider & 75 & 74 & 73 \\
\hline RN Care Manager & 25 & 26 & 27 \\
\hline Female $(\%)$ & 76 & 74 & 63 \\
\hline \multicolumn{4}{|l|}{ Age $(\%)$} \\
\hline $35-44$ years & 17 & 37 & 36 \\
\hline $45-64$ years & 55 & 58 & 45 \\
\hline Precept residents $(\%)$ & 34 & 42 & 36 \\
\hline $\begin{array}{l}\text { Part-time (Clinic } \\
<3 \text { days/week) (\%) }\end{array}$ & 24 & 21 & 23 \\
\hline \multicolumn{4}{|l|}{ Years at the VA $(\%)$} \\
\hline $1-3$ years & 15 & 14 & 14 \\
\hline $4-5$ years & 12 & 31 & 21 \\
\hline $6-10$ years & 0 & 0 & 36 \\
\hline $11-20$ years & 33 & 35 & 14 \\
\hline More than 20 years & 40 & 20 & 14 \\
\hline \multicolumn{4}{|l|}{ Patient Characteristics ${ }^{\mathrm{b}}$} \\
\hline Number & 7,518 & 4,666 & 4,759 \\
\hline $\begin{array}{l}\text { Mean Number of Patients } \\
\text { per Team }\end{array}$ & 940 & 778 & 793 \\
\hline Female $(\%)$ & 5 & 8 & 5 \\
\hline Age (mean years) & 63.0 & 62.9 & 63.7 \\
\hline Hypertension (\%) & 51 & 46 & 54 \\
\hline $\begin{array}{l}\text { Hypertensive with } \\
\text { uncontrolled Blood } \\
\text { Pressure }(\%)\end{array}$ & 24 & 24 & 23 \\
\hline Current Smokers (\%) & 11 & 9 & 11 \\
\hline Diabetes Mellitus (\%) & 24 & 23 & 24 \\
\hline Depression $(\%)$ & 18 & 19 & 17 \\
\hline $\begin{array}{l}\text { Post-Traumatic Stress } \\
\text { Disorder }(\%)\end{array}$ & 13 & 13 & 14 \\
\hline
\end{tabular}

${ }^{a}$ Data Source: Baseline and post-intervention staff surveys

${ }^{b}$ Data Source: VA Administrative Data

had uncontrolled BP. About $10 \%$ of the panel patients were current smokers. There were no significant baseline differences in staff or patient characteristics by study arm or campus.

\section{Impact of Panel Management Interventions on Blood Pressure (Table 2)}

Mean systolic BP among hypertensive patients decreased from $129.8 \mathrm{mmHg}$ at baseline to $128.7 \mathrm{mmHg}$ postintervention $(p<0.001)$. Mean diastolic BP decreased slightly from 74.4 to $73.9 \mathrm{mmHg}$ ( $p=0.003$ ). The proportion of patients with uncontrolled BP (systolic $>140$ or diastolic $>90$ ) decreased from 21.9 to $20.6 \%$ ( $p=0.18)$. However, these reductions in systolic, diastolic, and uncontrolled BP did not differ among study arms. Regression analysis, controlling for baseline BP and clustering within PCP, revealed no significant differences among study arms in mean systolic or diastolic BP values post-intervention. The effect of clustering was limited, as ICC values ranged from 0.007 to 0.013 . There were no differences between the PMA Support and the PMA-plusEducation teams. 
Table 2 Change in Mean Blood Pressure (BP) Values Among Hypertensive Patients, and Percent with Uncontrolled Blood Pressure by Study Group from Baseline to Post Intervention

\begin{tabular}{|c|c|c|c|c|c|c|c|c|c|c|}
\hline \multirow[t]{3}{*}{$\overline{\text { Outcome }}$} & \multirow{2}{*}{\multicolumn{3}{|c|}{$\begin{array}{l}\text { Control } \\
(N=1,648)\end{array}$}} & \multicolumn{6}{|c|}{ Intervention } & \multirow[t]{3}{*}{$\mathbf{p}^{*}$} \\
\hline & & & & \multicolumn{3}{|c|}{$\begin{array}{l}\text { PMA Support } \\
(N=1,074)\end{array}$} & \multicolumn{3}{|c|}{$\begin{array}{l}\text { PMA+Education } \\
(N=1,025)\end{array}$} & \\
\hline & Baseline & Post & Change & Baseline & Post & Change & Baseline & Post & Change & \\
\hline Mean (SD) Systolic BP mm & $\begin{array}{l}130.3 \\
(14.8)\end{array}$ & $\begin{array}{l}128.7 \\
(14.9)\end{array}$ & $\begin{array}{l}-1.6 \\
(15.8)\end{array}$ & $\begin{array}{l}128.9 \\
(15.3)\end{array}$ & $\begin{array}{l}128.3 \\
(14.7)\end{array}$ & $\begin{array}{l}-0.7 \\
(15.7)\end{array}$ & $\begin{array}{l}129.6 \\
(14.6)\end{array}$ & $\begin{array}{l}128.8 \\
(15.2)\end{array}$ & $\begin{array}{l}-0.8 \\
(15.9)\end{array}$ & 0.66 \\
\hline Mean (SD) Diastolic BP mm & $\begin{array}{l}75.0 \\
(10.8)\end{array}$ & $\begin{array}{l}74.6 \\
(10.2)\end{array}$ & $\begin{array}{l}-0.4 \\
(9.7)\end{array}$ & $\begin{array}{l}73.7 \\
(11.1)\end{array}$ & $\begin{array}{l}73.4 \\
(10.5)\end{array}$ & $\begin{array}{l}-0.3 \\
(10.0)\end{array}$ & $\begin{array}{l}74.8 \\
(11.0)\end{array}$ & $\begin{array}{l}74.3 \\
(11.0)\end{array}$ & $\begin{array}{l}-0.5 \\
(9.9)\end{array}$ & 0.51 \\
\hline \multirow[t]{2}{*}{ Outcome } & \multicolumn{3}{|l|}{$\begin{array}{l}\text { Control } \\
(N=369)\end{array}$} & \multicolumn{3}{|c|}{$\begin{array}{l}\text { PMA Support } \\
(N=235)\end{array}$} & \multicolumn{3}{|c|}{$\begin{array}{l}\text { PMA+Education } \\
(N=216)\end{array}$} & $\mathrm{p}^{*}$ \\
\hline & Baseline & Post & Change & Baseline & Post & Change & Baseline & Post & Change & \\
\hline 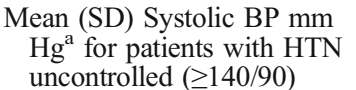 & $\begin{array}{l}150 \\
(11.6)\end{array}$ & $\begin{array}{l}137.1 \\
(15.8)\end{array}$ & $\begin{array}{l}-12.9 \\
(15.8)\end{array}$ & $\begin{array}{l}150.2 \\
(10.6)\end{array}$ & $\begin{array}{l}137.8 \\
(15.0)\end{array}$ & $\begin{array}{l}-12.4 \\
(16.1)\end{array}$ & $\begin{array}{l}149.5 \\
(10.5)\end{array}$ & $\begin{array}{l}137.5 \\
(16.2)\end{array}$ & $\begin{array}{l}-12.0 \\
(16.3)\end{array}$ & 0.63 \\
\hline 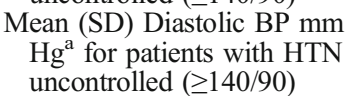 & $\begin{array}{l}84.0 \\
(11.4)\end{array}$ & $\begin{array}{l}77.9 \\
(10.7)\end{array}$ & $\begin{array}{l}-6.1 \\
(9.6)\end{array}$ & $\begin{array}{l}82.1 \\
(11.8)\end{array}$ & $\begin{array}{l}76.4 \\
(11.6)\end{array}$ & $\begin{array}{l}-5.7 \\
(9.9)\end{array}$ & $\begin{array}{l}84.8 \\
(10.7)\end{array}$ & $\begin{array}{l}78.6 \\
(11.8)\end{array}$ & $\begin{array}{l}-6.2 \\
(10.7)\end{array}$ & 0.71 \\
\hline $\begin{array}{l}\% \text { HTN Uncontrolled } \\
(\geq 140 / 90)^{\mathrm{b}}\end{array}$ & 22.4 & 20.2 & -2.2 & 21.9 & 21.7 & -0.2 & 21.1 & 20.0 & -1.1 & 0.76 \\
\hline
\end{tabular}

Of 869 patients with uncontrolled BP at baseline, $56 \%$ had a controlled mean BP reading post-intervention. Their mean systolic BP decreased from $146.1 \mathrm{mmHg}$ at baseline to $135.8 \mathrm{mmHg}$ post-intervention (mean change $-10.3 \mathrm{mmHg}$, SD 18.9, $p<0.0001)$, and mean diastolic BP decreased from 82.4 to $76.6 \mathrm{mmHg}$ (mean change $-5.8 \mathrm{mmHg}$, SD 11.3, $p<0.0001)$. However, these reductions did not differ significantly among the study arms.

\section{Impact of Panel Management on Smoking Outcomes (Table 3)}

Following the intervention, $83 \%$ of 362 smokers reported smoking in the last 30 days. Ninety percent of smokers reported quitting for at least 1 day, and $64 \%$ reported quitting for at

Table 3 Self-Reported Smoking Status and Quit Attempts PostIntervention by Study Group

\begin{tabular}{|c|c|c|c|c|}
\hline \multirow{3}{*}{$\begin{array}{l}\text { Smoking } \\
\text { Outcomes }^{\text {a }}\end{array}$} & \multirow{3}{*}{$\begin{array}{l}\text { Control } \\
(N=141)\end{array}$} & \multicolumn{2}{|l|}{ Intervention } & \multirow[t]{3}{*}{$p^{*}$} \\
\hline & & PMA Support & $\begin{array}{l}\text { PMA+ } \\
\text { Education }\end{array}$ & \\
\hline & & $(N=92)$ & $(N=129)$ & \\
\hline $\begin{array}{l}\text { Smoked in last } \\
30 \text { days }(\%)\end{array}$ & 84.4 & 77.2 & 84.5 & 0.28 \\
\hline $\begin{array}{l}\text { Quit for at least } \\
1 \text { day }(\%)\end{array}$ & 90.8 & 92.4 & 87.6 & 0.47 \\
\hline $\begin{array}{l}\text { Quit for at least } \\
1 \text { week }(\%)\end{array}$ & 63.8 & 64.1 & 63.6 & 0.99 \\
\hline
\end{tabular}

${ }^{a}$ Surveys at baseline and post-intervention of randomly selected sample of patients identified as current smokers based on their most recent clinical reminder result in the medical record

* $p$ values for overall comparison among study arms in adjusted logistic regression model, controlling for clustering of patients within providers least a week. However, there were no significant differences in smoking rates or quit attempts by study group.

\section{Secondary Outcomes (Table 4)}

Patients on intervention teams were more likely to receive NRT prescriptions for smoking than patients on control teams $(\mathrm{OR}=1.4 ; 95 \%$ CI 1.2-1.6). Hypertensive patients on intervention teams were also more likely to enroll in the Telehealth $(\mathrm{OR}=1.7,95 \% \mathrm{CI} 1.4-2.1)$ and MOVE! (OR=1.2; $95 \% \mathrm{CI}$ 1.1-1.6) programs than patients on control teams.

\section{Implementation of the Intervention}

In total, PMAs reached 783 intervention smoker and hypertensive patients by phone $(20 \%)$ and 3,088 by mail $(79 \%)$ during the 8-month intervention. Of 535 patients contacted to make a PACT appointment, $49 \%$ scheduled one and over 200 patients made appointments for a chronic disease related service such as Telehealth, MOVE!, or a hypertension sharedmedical visit.

\section{Effect of Panel Management Dose on Blood Pressure Control for Intervention Teams}

PMAs attended all bi-weekly PACT meetings, but teams actually met only $79 \%$ of the time (range, 33-100 \% of all potential meetings). The proportion of patients with controlled BP post-intervention was higher for those on intervention teams that met more often with the PMA (Pearson's $r=0.68$, $p=0.016$ ). The proportion with controlled BP postintervention was also higher for teams on which PMAs reached more patients by phone $(r=0.58, p=0.048)$. 
Table 4 Impact of PM Support on Secondary Outcomes Following the Intervention

\begin{tabular}{|c|c|c|c|c|}
\hline & \multirow[t]{2}{*}{ Control } & \multicolumn{2}{|l|}{ Intervention } & \multirow[t]{2}{*}{$\mathbf{p}^{*}$} \\
\hline & & PMA Support & PMA +Education & \\
\hline Smokers receiving nicotine replacement therapy $(\%)$ & 6.2 & 7.5 & 8.7 & $<0.001$ \\
\hline Panel assigned patients enrolled in Telehealth** (\%) & 2.8 & 3.6 & 4.2 & $<0.001$ \\
\hline Obese hypertensive patients attending 1 or more MOVE!** sessions $(\%)$ & 15.7 & 16.2 & 16.8 & 0.04 \\
\hline Smoking or hypertensive patients with a PC visit in the last 12 months (\%) & 87.0 & 87.0 & 87.3 & 0.89 \\
\hline Smoking or hypertensive patients with a PC visit in the last 6 months (\%) & 74.0 & 74.0 & 72.5 & 0.24 \\
\hline
\end{tabular}

*Adjusted logistic regression models controlling for clustering (PCP assignment)

**Telehealth is a telephone based monitoring and management program for patients with chronic illness at the VA; MOVE! is the VA's weight management program

\section{Staff Experiences with Panel Management}

At baseline, only $26 \%$ of staff felt they had sufficient training or education in panel management. This increased to $64 \%$ post-intervention, with no significant differences among study arms. Most staff ( $80 \%)$ assigned to an intervention team felt the PMA was a useful resource for their team and $73 \%$ wanted to continue working with a PMA. Only $26 \%$ said the PMA took too much of their time, while only $40 \%$ said they would continue using panel management strategies when the PMA left the team.

\section{DISCUSSION}

In this pragmatic, cluster-randomized trial of panel management support and education for primary care teams caring for veterans with hypertension and smoking, there were no significant differences in the primary outcomes of BP control or smoking cessation compared to baseline levels. However, some secondary outcomes did improve. Patients on intervention teams were more likely to receive prescriptions for NRT and were more likely to participate in VA support services of MOVE! and Telehealth. Patients on teams that met more frequently with their PMA or were reached more frequently by phone were more likely to have controlled BP by the end of the study.

The lack of intervention effectiveness on primary outcomes has several potential explanations. PMAs were able to reach only a modest proportion of targeted patients with hypertension and smoking on the intervention teams due to the limited dosage permitted by the 8 -month intervention. Behavioral interventions often require multiple contacts with patients to optimize their effectiveness. ${ }^{32}$ The positive impact on secondary outcomes and the dose response of PMA contact with PACT staff and patients on BP control suggest that a longer intervention may result in improvements in the primary clinical outcomes of hypertension control and smoking cessation. With $78 \%$ of hypertensive patients having controlled BP at baseline, this "ceiling" effect may have limited the impact of the intervention. PMAs were introduced into newly formed teams; intact teams with a history of working together effectively might have made better use of PMAs. The education "dose" was brief by design to better integrate into the teams' schedules, but this likely limited its impact, given the paucity of education on panel management for most health professions. Providing monthly reports of patients with uncontrolled hypertension and smoking to providers on control group teams may have changed their behavior and diminished the impact of the intervention. The use of self-report for cigarette smoking may have led to underreporting of smoking status; ${ }^{33}$ however, the rate of underreporting was less than $1 \%$ in a biochemical analysis of National Health and Nutrition Examination Survey (NHANES) respondents from 2001 to $2008 .{ }^{34}$

\section{CONCLUSIONS}

Although the intervention did not improve clinical outcomes, the lessons learned are worth highlighting to guide further study and implementation of panel management. Clinicians welcomed support to accomplish this new set of panel management tasks. Panel management interventions should be long enough to optimize the dose of PMA outreach in order to realize behavior change and improved clinical outcomes. PMAs should be embedded in regular team workflow to maximize communication regarding panel management tasks and outcomes. Panel management should target clinical problems and populations most likely to benefit from outreach and enhanced patient engagement.

This study raises additional questions. What is the optimal dose of panel management required to improve population outcomes? If effective, is panel management cost-effective? Are there models of team practice that can succeed in panel management without additional PMA staff? How should interdisciplinary clinical teams be trained to optimize panel management performance? Which routine tasks and interventions can be safely and effectively delegated to non-clinical staff? What technological support is needed to maximize panel management?

As physicians, practices, and healthcare systems seek to optimize the health of the populations they serve, panel management remains an intriguing approach. Further research will pursue answers to the questions noted above and guide models for doctors to effectively scale up their clinical expertise to improving population health. 
Acknowledgements: The research leading to these results was funded through an HSR\&D grant from the VA Health Services Research \& Development Service (EDU 08-428-2).

Conflict of Interest: The authors and all other contributors do not report any conflicts of interest.

Corresponding Author: Mark D. Schwartz, MD; Department of Population HealthNew York University School of Medicine, 227 E. 30th Street, Rm. 704, New York, NY 10016, USA (e-mail: mark.schwartz@nyumc.org).

\section{REFERENCES}

1. CMS. The Federally Qualified Health Center (FQHC) Advanced Primary Care Practice Demonstration Center for Medicare and Medicaid Innovation; 2013.

2. Kimura J, DaSilva K, Marshall R. Population management, systemsbased practice, and planned chronic illness care: Integrating disease management competencies into primary care to improve composite diabetes quality measures. Dis Manag. 2008;11:13-22.

3. Loo TS, Davis RB, Lipsitz LA, Irish J, Bates CK, Agarwal K, et al. Electronic medical record reminders and panel management to improve primary care of elderly patients. Arch Intern Med. 2011;171(17):1552-8.

4. Grant RW, Hamrick HE, Sullivan CM, Dubey AK, Chueh HC, Cagliero E, et al. Impact of population management with direct physician feedback on care of patients with type 2 diabetes. Diabetes Care. 2003;26(8):2275-80.

5. Payne TH, Galvin M, Taplin SH, Austin B, Savarino J, Wagner EH. Practicing population-based care in an HMO: evaluation after 18 months. HMO Pract. 1995;9(3):101-6.

6. McCulloch DK, Price MJ, Hindmarsh M, Wagner EH. A populationbased approach to diabetes management in a primary care setting: early results and lessons learned. Eff Clin Pract. 1998;1(1):12-22.

7. Neuwirth E, Schmittdiel J, Tallman K, Bellows J. Understanding PM: A comparative study of an emerging approach to population care. The Permanente Journal. 2007;11:12-20.

8. Chen EH, Bodenheimer T. Improving Population Health Through TeamBased Panel Management. Arch Intern Med (American Medical Association). 2011;171(17):(2 pages).

9. Norris SL, Nichols PJ, Caspersen CJ, Glasgow RE, Engelgau MM, Jack $\mathbf{L}$, et al. The effectiveness of disease and case management for people with diabetes. A systematic review. Am J Prev Med. 2002;22(4 Suppl):15-38.

10. Simon GE, VonKorff M, Rutter C, Wagner E. Randomised trial of monitoring, feedback, and management of care by telephone to improve treatment of depression in primary care. BMJ. 2000;320(7234):550-4.

11. Adair R, Christianson J, Wholey DR, White $\mathbf{K}$, Town R, Lee S, et al. Care guides: employing nonclinical laypersons to help primary care teams manage chronic disease. J Ambul Care Manage. 2012;35(1):27-37.

12. Rosland A, Nelson $\mathbf{K}$, Sun $\mathbf{H}$, et al. The Patient Centered Medical Home in the Veterans Health Administration. Am J Manag Care. 2013;9(7):263-72

13. True G, Butler A, Lamparska B, Lempa M, Shea J, Asch D, et al. Open Access in the Patient-Centered Medical Home: Lessons from the Veterans Health Administration. J Gen Intern Med. 2012;28(4):539-45.

14. Borzecki A, Wong A, Hickey E, Berlowitz D. Hypertension control: How well are we doing? Arch Intern Med. 2003;163:2705-11.
15. Yoon P, Gillespie C, George M, Wall H. Control of hypertension among adults - National Health and Nutrition Examination Survey, United States, 2005-2008. Morb Mortal Wkly Rep. 2012;61(suppl):19-25.

16. CDC. Health, United States 2012 with Special Feature on Emergency Care. U.S. Department of Health and Human Services, National Center for Health Statistics; 2013

17. VHA. 2010 Survey of Veteran Enrollees' Health and Reliance Upon VA. Department of VA Affairs: Veteran Health Administration; 2011.

18. Hoffman R. Memorandum to the Deputy Under-Secretary for Health, Veterans Health Administration: Business case for proposed elimination of the current co-payment for smoking cessation counseling services. Office of the Assistant Deputy Under Secretary for Health: Veterans Health Administration; November 10, 2003.

19. Sherman S. A framework for tobacco control: lessons learnt from Veterans Health Administration. BMJ. 2008;336(7651):1016-9.

20. Hartocollis A. With Some Hospitals Closed After Hurricane, E.R.'s at Others Overflow. New York Times; 2012.

21. Gutnick D, Reims K, Davis C, Gainforth H, Jay M, Cole S. Brief Action Planning to Facilitate Behavior Change and Support Patient Self-Management. JCOM. 2014;21(1):18-29.

22. Savarimuthu S, Jensen A, Schoenthaler A, Dembitzer A, Tenner C, Gillespie C, et al. Developing a toolkit for panel management: improving hypertension and smoking cessation outcomes in primary care at the VA. BMC Family Practice. 2013;14:176-84.

23. VHA. Primary Care Almanac. Washington, DC: VHA Support Service Center; 2010.

24. Barnett PG, Hamlett-Berry K, Sung HY, WM. Health Care Expenditures Attributable to Smoking in Military Veterans. Nicotine Tob Res. 2014 Sep 19.

25. Strauss SM, Jensen AE, Bennett K, Skursky N, Sherman SE, Schwartz MD. Clinicians' panel management self-efficacy to support their patients' smoking cessation and hypertension control needs. Translational Behavioral Medicine. 2014:1-9.

26. Sherman S, Fotiades J, Rubenstein L, et al. Teaching systems-based practice to PC physicians to foster routine implementation of evidencebased depression care. Acad Med. 2007;82:168-75.

27. Schulz K, Altman D, Moher D, Group C. CONSORT 2010 Statement: Updated Guidelines for Reporting Parallel Group Randomized Trials. Ann Intern Med. 2010;152:726-32.

28. Campbell M, Elbourne D, Altman D, Group C. CONSORT Statement: Extension to cluster randomized trials. BMJ. 2004;328:654-5.

29. Zwarenstein M, Treweek S, Gagnier J, Altman D, Tunis S, Haynes B, et al. Improving the reporting of pragmatic trials: an extension of the CONSORT statement. BMJ. 2008;337:a2390.

30. Institute S. 9.3 ed. Cary, North Carolina.

31. Donner A, Klar N. Design and analysis of cluster randomization trials in health research: London Arnold Publishers; 2000.

32. Ogedegbe G, Chaplin W, Schoenthaler A, Statmen D, Berger D, Richardson R, et al. A Practice-Based Trial of Motivational Interviewing and Adherence in Hypertensive African Americans. Am J Hypertens. 2008;21(10): 1137-43.

33. Connor Gorber S, Schofield-Hurwitz S, Hardt J, et al. The accuracy of self-reported smoking: a systematic review of the relationship between selfreported and cotinine-assessed smoking status. Nicotine Tob Res. 2009;11:12-24.

34. Yeager DX, Krosnick JA. The Validity of Self-Reported Nicotine Product Use in the 2001-2008 National Health and Nutrition Examination Survey. Med Care. 2010;48:1128-1132. 